\title{
Teaching undergraduate mathematics fully online: a review from the perspective of communities of practice
}

\author{
Sven Trenholm ${ }^{1 *}$ (D) and Julie Peschke ${ }^{2}$
}

\author{
* Correspondence: Sven.Trenholm@ \\ unisa.edu.au \\ ${ }^{1}$ School of Education, University of \\ South Australia, Mawson Lakes \\ Campus, Office G2-27 (Garth \\ Boomer Building), Adelaide, SA \\ 5095, Australia \\ Full list of author information is \\ available at the end of the article
}

\begin{abstract}
The use of fully online (FO) mathematics teaching has been increasing worldwide. Despite claims and findings that mathematics is more challenging to teach $\mathrm{FO}$ than face-to-face (F2F), we know little about FO mathematics teaching. In this paper, we address this gap by working to elucidate the differences between teaching in the FO and F2F modalities. We do this by examining FO and F2F teaching from the perspective of Communities of Practice (Wenger, Social learning systems and communities of practice, 2010) by comparing and contrasting current FO practices (or "ways of doing") in the general undergraduate education community with current F2F practices in the undergraduate mathematics community. We identify six key differences between the two paradigms, which we recast to spotlight areas for technological and pedagogical development.
\end{abstract}

Keywords: Undergraduate mathematics, Pedagogy, Online teaching, E-learning, Community of practice

\section{Background}

The online medium has opened up a whole new vista of education possibilities. Today, the landscape of the traditional face-to-face (F2F) undergraduate classroom has metamorphosed into an osmosis of modalities (Borba et al., 2016), from a mix of online and face-to-face pedagogical strategies to fully online (FO) teaching methods (Blair, Kirkman, \& Maxwell, 2012). The former (F2F), though undergoing modifications in the teacher-student experience, such as the flipped classroom and the interjection of computer-mediated applications, largely remains a campus- and live lecture-based experience. The latter (i.e. FO) is typically characterised by the separation, in both space and time (i.e. asynchronous ${ }^{1}$ ), of the teacher(s) and students (Miller, 2014). Historically associated with distance education, FO teaching has been steadily growing (Allen \&

\footnotetext{
${ }^{1}$ There are some exceptions. Students being taught entirely online may, for example, ask for help over the phone or, if they also study on-campus, using live "office hours". And, of course, other course-related learning experiences are not devoid of synchronicity: Student-content interactions (e.g. use of paper-based textbooks) are always synchronous and student-technology interactions are generally synchronous (e.g. use of CAA with immediate feedback; cf. Moore, 2007).
}

() The Author(s). 2020 Open Access This article is licensed under a Creative Commons Attribution 4.0 International License, which permits use, sharing, adaptation, distribution and reproduction in any medium or format, as long as you give appropriate credit to the original author(s) and the source, provide a link to the Creative Commons licence, and indicate if changes were made. The images or other third party material in this article are included in the article's Creative Commons licence, unless indicated otherwise in a credit line to the material. If material is not included in the article's Creative Commons licence and your intended use is not permitted by statutory regulation or exceeds the permitted use, you will need to obtain permission directly from the copyright holder. To view a copy of this licence, visit http://creativecommons.org/licenses/by/4.0/. 
Seaman, 2017) and is increasingly being used by on-campus students, and less exclusively by remote students (Woo et al., 2008).

A typical FO course ${ }^{2}$ is usually accessed through an institutional Learning Management System (LMS) such as Moodle (which is open source), Blackboard, Canvas, Brightspace and others. Each provides a choice of tools for the inclusion of text, graphics and video casts as well as web links to outside resources, ready access to eTexts, some machine-marked testing mechanisms, inbuilt communication channels (e.g. discussion forums), interactive scheduling of activities, and drop boxes for assignments with grade books for recording. In short, all course content and interactivity is typically stored and managed in a course LMS while other websites may also be used, for example, to access textbook resources, computer-aided assessment and/or computer algebra systems. However, all human communication is typically channelled via the use of a computer mouse and keyboard and received through a computer (desktop, laptop and increasingly mobile) screen and/or a speaker.

With regards to assessment practice, a typical FO mathematics course uses a mix of machine-marked testing in LMS's or publisher eTexts and/or the writing of proctored hand-written exams. An example of an online testing facility which allows for both machine-marked and instructor-marked quizzes or examinations is Moebius with the Maple TA testing application (backed by a powerful Maple software engine) embedded in the content. Maple TA offers a wide array of question types, including the "essay" type which may be used for the solution of procedural problems. The latter type is supported by a text editor and a Math palette. Whether hand-written or completed online through a testing facility, examinations are generally proctored. Two modes of proctoring are now available. The first is by an invigilator in a registered public institution such as an educational institution, a library or a government office. The second is by a virtual invigilator which enables students to take exams from anywhere using a Web cam and a high speed Internet connection. ProctorU, Examity and Verificient are some examples of online proctors in North America.

Research suggests FO teaching of undergraduate mathematics is not working well (Trenholm, Peschke, \& Chinnappan, 2019). Large scale US research ( $n>14,000$ students), for example, suggests undergraduate mathematics students in FO learning spaces do not fare as well as those in F2F classrooms (e.g. academic achievement: Vilardi \& Rice, 2014; attrition: Xu \& Jaggars, 2011). These findings concur with claims FO mathematics teaching is challenging to deliver (Glass \& Sue, 2008; Lokken, 2011) and that students are dissatisfied with their FO mathematics courses (Mills \& Raju, 2011).

Despite this, many see FO teaching as having the potential to usher in major pedagogical innovation in mathematics. Some see, for example, the relative student anonymity as helping students feel less threatened as compared to live F2F settings (Smith, Ferguson, \& Caris, 2003), and as enabling "playful exploration" (Rosa \& Lerman, 2011, p.84). Still others envision an opportunity to disrupt traditional teaching processes to the benefit of students and their learning (Borba et al., 2016; Trenholm, Alcock, \& Robinson, 2016).

There is some apparent tension between actual findings and claims of promise and some evidence suggests the asynchronous online teaching modality presents a

${ }^{2}$ Or "modules" in the UK context. 
challenging environment for teaching mathematics (Trenholm et al., 2016). In negotiating these challenges, others suggest there is resistance to change within the undergraduate mathematics teaching community (Sfard, 2014). Indeed, the actions of this community, how its members react to, adapt or innovate to this new modality, including how hurdles or roadblocks may be surmounted, these are critical research foci and questions. From this perspective, we therefore propose a closer examination of the different communities that separately and together constitute the FO undergraduate mathematics teaching community. As a starting point, we focus our attention on the general FO undergraduate education community and the F2F undergraduate mathematics community.

In particular, in this paper we undertake our examination by making use of the Communities of Practice (CoP; Wenger, 1998, 2010) lens to compare and contrast current FO teaching practices operating in the general undergraduate education community with current F2F practices in the undergraduate mathematics community. In so doing, we share what we argue to be the current synchronicities and dichotomies between these two communities. Where little is currently known about FO undergraduate mathematics education (Borba et al., 2016), we believe this new knowledge will help advance the development of more effective pedagogical practices in both FO and F2F mathematics teaching.

\section{Theoretical background}

$\mathrm{CoP}$ is a social learning theory originally proposed by Lave and Wenger (1991) and developed by Wenger (1998). Wenger's focus is on a social theory of learning, seeing learning as encompassing four interconnected and mutually defining components: community (learning as belonging), identity (learning as becoming), meaning (learning as experience), and practice (learning as doing). Various other concepts are introduced as Wenger explores these four components of learning.

For Wenger (1998), a community has three defining characteristics relating to the practice with which the community is associated: Joint Enterprise, Mutual Engagement and Shared Repertoire (p. 73). Loosely these refer to the shared goals, activity and resources of the community. Participation in that community leads to participants developing identities which involve engagement, imagination and alignment: "1) engagement - active involvement in mutual processes of negotiation of meaning; 2) imagination - creating images of the world and seeing connections through time and space by extrapolating from our own experience; 3 ) alignment - coordinating our energy and activities in order to fit within broader structures and contribute to broader enterprises." (p. 173-4; see also Jaworski, 2009). Wenger further suggests that practice connotes "doing but not just doing in and of itself, it is doing in a historical and social context that gives structure and meaning to what we do" (p.47). As Jaworski (2009) states, a CoP develops "over time ... [with] norms and expectations of what will be done and how" (p.1586). In this sense, successful participation in specific communities of practice may be seen as contingent on a mutual understanding about "ways of doing" or social norms existing within a community.

In each community, new participants have to learn to be a member of the community, doing what others do, experiencing the meaning associated with doing, developing 
a CoP identity, becoming part of the CoP, and ultimately feeling the nature of belonging to the CoP. When two or more diverse communities work together towards a common goal, we can argue there must be an alignment within these communities regarding "ways of doing"; for example, how teachers, students and assessment practices address common goals for student learning. In order for such alignment to develop some form of "brokering" (Wenger, 1998) can be essential which looks critically at the boundaries of the two practices, with experts in the two communities acting as brokers to help overcome challenges and achieve common goals. Wenger writes (p. 109), "brokers are able to make new connections across communities of practice, enable coordination, and - if they are good brokers - open new possibilities for meaning". He goes on to say (p.109), "[i] t also requires the ability to link practices by facilitating transactions between them, and to cause learning by introducing into a practice elements of another."

In our study, we use the CoP lens to compare and contrast the practices, which we simply refer to as "ways of doing", within the general undergraduate community of FO teachers and the community of undergraduate mathematics teachers (who participate largely in F2F courses). From this basis we seek to act as brokers, helping both the FO and F2F undergraduate mathematics teaching communities overcome challenges and achieve the common goal of advancing student learning.

\section{Related research}

The use of the theory of CoP as an analytical study framework has an established and developing history in general (Cox, 2013), in mathematics (Roos \& Palmér, 2015) and in online (Smith, Hayes, \& Shea, 2017) higher education research. In general higher education, for example, researchers have investigated the use of F2F (Viskovic, 2006) and FO (Riesland, Jacobson, Snare, \& Fehrenbacher, 2016; Velez-Solic \& Banas, 2012) CoPs to help develop university teachers in their teaching practice. In undergraduate mathematics education, researchers have investigated existing F2F teacher CoPs (Biza, Jaworski, \& Hemmi, 2014; Jaworski, 2009) as well as their development (King \& Cattlin, 2017). No known studies of FO undergraduate mathematics teacher CoPs were found.

The successful development of FO teachers is said to involve the collaborative efforts of at least three different communities: administrators, academics themselves and those involved in professional development (Covington, Petherbridge, \& Warren, 2005). The notion of intersecting communities of practice is not new. Indeed, Lave and Wenger (1991) define a CoP as "a set of relations among persons, activity, and world over time and in relation with other tangential and overlapping communities of practice. (emphasis ours; p. 98)."

At least a few case studies have investigated the intersection of CoPs. Chambers and Armour (2011), for example, were interested in examining the "nature and quality" of learning received by physical education student teachers (p.598). They investigated the intersection of the various related communities involved in the training of their students (e.g. students, teacher educators and supervising/mentor teachers). In another example, Kisiel (2010) was interested in investigating the collaboration between one urban primary school and a nearby aquarium, focusing on the intersection of these two broad CoPs. In both case studies, insights were gained to aid in future related development efforts. 
In F2F university mathematics, the $\mathrm{CoP}$ is considered to comprise of at least four different communities - researchers and teachers, undergraduate and postgraduate students (Biza et al., 2014). As Biza et al. (2014) confirm, understanding "the interaction of and tension between different communities" is an important study focus. Meanwhile, in the field of online and distance education only one relevant study was found. Correia and Davis (2008) investigated the intersection of two communities of practice - the program team (composed of administrators, teachers and online course designers) and the online course community (composed of the course teacher and students interacting online). Their case study analysis also provided useful insights, particularly around overcoming conflicts and challenges in pursuing their common goal of advancing student learning.

Taken together prior work suggests use of the CoP framework has productive potential for elucidating the reasons for and possible solutions to current challenges teaching FO mathematics. We now turn to detailing our use of the CoP framework in this study.

\section{Methodology}

This paper is a reflection on our combined experience of more than 40 years as FO mathematics teachers actively involved in researching and developing FO mathematics teaching and assessment practices. This includes our related experiences in two countries and institutions, both nationally and internationally recognised for their work in FO teaching and associated research and development - The State University of New York ("Open SUNY"; http://navigator.suny.edu/) and Athabasca University ("Canada's Open University"; http://www.athabascau.ca/).

Sven Trenholm reports from his experiences first as a F2F and FO undergraduate mathematics teacher (US), second as a graduate student focused on FO mathematics teaching (US and UK) and now as fulltime research academic (Australia): "I have long had a fascination with computers and their use in mediating human interactivity. In the 11 years I worked at SUNY as a fulltime mathematics teacher I naturally gravitated to exploring all levels of computer-mediated teaching. Concomitantly, I formally began researching the nature of associated pedagogies, particularly around FO mathematics teaching. My personal and professional interest has long rested on examining the qualitative nature of FO mathematics teaching and learning. This continues to be a driving force for my own reflections and practice".

Julie Peschke, in contrast, did not appreciate the invasion of computer devices into the undergraduate mathematics classroom - neither calculators, nor the use of mathematical software nor the advent of FO teaching and learning: "A purist at heart but practical by nature and curious to explore, I found myself agreeing to participate in projects involving the regular use of mathematical software in a F2F Calculus classroom, contributing to an online web site for a course in Linear Algebra and finally accepting a position at Athabasca University, the first open, online university in Canada, teaching Statistics. This crossing of divides has profoundly re-shaped my pedagogy and altered my perception of what it takes to learn the abstractions of mathematical thought".

Though this paper should be considered a reflective piece, it is informed by our ongoing reading of the literature. Over the years we have conducted extensive and 
ongoing reviews of the associated F2F and FO research literature, making use of online search engines (e.g. Google Scholar, EBSCOhost, ERIC) with keywords such as "mathematics", "lecturing", "online" and "internet", particularly focussing on articles in the fields of mathematics and distance education. We were interested in the nature of FO general and F2F mathematics specific teaching and assessment practices, specifically at the undergraduate level. This included, for example, the F2F literature on undergraduate mathematics lecturing, the literature on the nature of FO general undergraduate courses and FO undergraduate mathematics courses. This process intensified during the years we separately undertook PhD studies focused in this area (see Peschke, 2014a; Trenholm, 2013) and, in some ways, the reflections we present in this paper represent a synthesis of our PhD work.

Overall, our collective reflections combine approximately 40 years of practical experience and scholarly study. Upon this foundation we make use of $\mathrm{CoP}$ as a critical lens and focus on the teacher CoP notion of "ways of doing", which we define as the shared ways and means of teaching in a particular community. ${ }^{3}$ Specifically, we focus on comparing the practices in two communities of teachers: how FO undergraduate courses, in general, tend to be taught and delivered with how F2F undergraduate mathematics courses, in particular, tend to be taught and delivered. As we will cover next, this process leads us first to argue six foundational differences in "ways of doing" between the undergraduate general FO and F2F mathematics teaching communities.

\section{Results}

In the sections below we outline six differences in "ways of doing" between the general FO undergraduate and F2F undergraduate mathematics CoPs which, for readability purposes, we simply refer to as the general FO and F2F mathematics CoPs. In the main, while many reflect the constraints of the FO environment, ${ }^{4}$ as we argue in the coming discussion, they also present avenues for positive change.

\section{Student-led learning}

As a first difference, the general FO mode of teaching-learning requires a deeper engagement of students than occurs in F2F (Anderson \& Elloumi, 2008): FO students have to read/view what they are given online; they have to work with it before they can ask questions of a teacher or co-learners. In short, students must take a role in leading their own learning and if they choose not to engage, nothing happens.

However, we see from extensive research that F2F mathematics teaching practices tend to be predominantly "transmissionist" and teacher, not student-led (Nelson Laird, Shoup, Kuh, \& Schwarz, 2008), with a disciplinary culture that tends to engender teacher dependence and not student independence. This is not to suggest that transmissionist teaching is the problem. Rather it is what the FO medium does to that

\footnotetext{
${ }^{3}$ In other work, Corriveau (2017) studied the secondary-to-tertiary mathematics transition by comparing the "ways of doing" mathematics as informal and "non-explicit ways of acting, thinking, and reasoning" (p.141). In contrast, in the context of this reflection, we consider "ways of doing" as mostly explicit and immediately observable.

${ }^{4} \mathrm{We}$ recognise cultures and constraints also exist in the F2F environment, which is more established, and therefore possibly harder to change. Developmental practice in F2F teaching is currently a focus of considerable interest and communication (e.g. recently launched International Journal of Research in Undergraduate Mathematics Education).
} 
teaching (e.g. a reliance upon recorded versus live lectures) and the requirements it places on students to take more control over their consumption (e.g. rate and amount) of new knowledge. This contrasts with a F2F mathematics CoP that envisions teachers, largely, as controlling the flow and dissemination of all new information and associated interactivity. This apparent conflict is reflected in recent research that suggests mathematics teachers are struggling to adapt their practice to the virtual medium, particularly in relation to the nature of interactivity considered necessary for effective teaching compared to that which is available (Trenholm, 2013).

\section{Use of student discussion}

A second related difference is an emphasis on student-student online discussion (Swan, 2003), typically realized as a weighted part of FO course assessment schemes (Everson \& Garfield, 2008). And though many claim online discussion in FO mathematics courses has potential for advancing student learning (e.g. Everson \& Garfield, 2008), the strongest quantitative findings suggest, at the very least, that FO teachers do not perceive online discussion to be beneficial to their teaching (Finnegan, Morris, \& Lee, 2009). This is consistent with qualitative research, at the school level, suggesting distance teaching of mathematics is primarily a "one-on-one" experience with little use of collaboration (Lowrie \& Jorgensen, 2012).

The dual emphasis on both student-led learning and discussion in FO courses, in general, is consistent with the prominent interest in and application of constructivist "approaches" (Rovai, 2004) in general FO teaching (see also Anderson \& Elloumi, 2008). This emphasis is interesting given the "waning" influence of constructivism in mathematics education at lower levels (Confrey \& Kazak, 2006, p.331), although perhaps not in higher education (Abdulwahed, Jaworski, \& Crawford, 2012).

On balance, problems with FO discussion should not be surprising given F2F mathematics has been found to be one of the disciplines least likely to use any discussion (Entwistle, 2009). Moreover, here again, we can see that established practices in the F2F mathematics CoP appear to conflict with those in the general FO CoP.

\section{Communicating mathematics}

A third related difference, and another possible reason for the lack of FO discussion, concerns the current ${ }^{5}$ nature of communicating mathematics in the general FO course context. Problems continue to persist with freely and extemporaneously communicating mathematical concepts via notation and diagrams (Prieto \& Holmes, 2014). In F2F mathematics, teachers commonly write on large boards, filling their space with mathematical notation and symbolism. In general FO teaching, where varied and different media may be used for communication purposes, issues can arise.

Evidence of these problems is apparent when discussing the two composite elements needed for online communication: computer hardware and software. First, while the qwerty-keyboard and mouse present a relatively natural fit with, for example, "textbased" disciplines, the same cannot be said for the heavily symbolic and diagrammatic nature of mathematics. Teachers may, for example, create their own notational systems

${ }^{5}$ While these reflections are, of course, limited by the state of ongoing technological development, we believe they represent the nature of communication in the majority of FO mathematics courses. 
(e.g. using $\operatorname{sqr}\left(\mathrm{x}^{\wedge} 2-y\right)$ for $\left.\sqrt{x^{2}-y}\right)$, scan and email, draw with a mouse or use tool palettes. Notwithstanding ongoing efforts to tackle this problem (Keady, Fitz-Gerald, Gamble, \& Sangwin, 2012), most current methods offer concessions to what is understood to be efficient and natural communication using, for example, pencil and paper writing or drawing (Smith, Torres-Ayala, \& Heindel, 2008). Second, the potential of current software appears limited to specific contexts or concepts, with some FO mathematics courses requiring the use of multiple websites - for example, the use of interactive software (e.g. GeoGebra), a textbook website providing computer-aided assessment and a separate virtual learning environment (VLE) each with their own toolbar/palettes and/or key commands (Engelbrecht \& Harding, 2005). In short, despite potential advantages to particular systems, learning the various rules, protocols ... of different systems for writing and communicating the same mathematics may be challenging, further taxing what many students already find to be a challenging discipline (Smith et al., 2008).

In CoP terms, these issues suggest some difficulty establishing the necessary "norms and expectations" needed to develop the FO mathematics CoP (Jaworski, 2009, p.1586). In consideration of diagrammatic thinking, for both students and teachers, signs must "acquire interindividual significance" in such a way that participants may "proceed uninterruptedly" from sign to sign (Voloshinov, 1973 as cited in Radford, 2008, p.15). That is, as the above issues suggest, the flow of communication in the FO mathematics $\mathrm{CoP}$ may not be as free-flowing or as facile as what is experienced in the F2F mathematics CoP. Moreover, consistent with ongoing technological developments, FO mathematics CoP communication norms appear in flux. They may even vary, for example, from course to course or teacher to teacher, such that expectations may be nonexistent. In contrast, in the case of the F2F mathematics CoP, there has been an established practice of communication whereby the medium of white/chalkboard largely obviates the need for communication through hardware and software.

\section{Gestures and multimodal communication}

Moreover, in further consideration of communicating mathematics, additional semiotic resources, common to F2F teaching (Arzarello, Paola, Robutti, \& Sabena, 2009), may be severely limited or non-existent in general FO teaching. In particular, there is a growing recognition of the need for multiple modes of communication in mathematics, such as verbal cues, gestures and facial expressions, all communication channels emerging research suggests tend to act as cognitive supports helping the learning process (Edwards, 2009). As this would seem to imply, when such communication resources are lacking, it may be more difficult for FO mathematics teachers to help develop students' conceptual understanding, as well as judge and monitor the state of that understanding (Trenholm, 2013).

Certainly, recorded lectures with a full body view of the teacher may provide many of these resources. However, this interaction is largely one way (teacher to student) and any online communication preceding or following a lecture viewing tends to be text/ symbol-based (though technology for video communication is improving). That is, FO students and teachers tend to write about maths, not speak, gesture, display eye movement. While these communication challenges have been noted in other disciplines 
(Hrastinski \& Stenbom, 2013), some claim a greater need for these resources exists in abstract disciplines such as mathematics (Edwards, 2009; Roth, 2001). That is, from a disciplinary perspective, through restrictions on their practice, members of the F2F mathematics CoP may struggle to surmount what most in the FO general CoP do not experience to be challenging.

\section{Timing in cycles of interactions}

As characteristically asynchronous, current FO teaching provides a different kind of reflective interactivity than what has, at least previously, been identified as helping develop students' understanding in mathematics. Some claim alternating periods of discussion and reflection are needed to develop a deeper understanding of mathematical ideas (Elbers, 2003). One characteristic of this interactivity is the timing, for example, in the recursive interactivity between a teacher's question, a student's answer and the teacher's feedback. Though little understood (cf. a summary of research on "wait time": Lerman, 2014), recent evidence suggests many teachers are struggling with the lack of real-time interactivity, as is characteristic in the multimodal communication described above, which they claim to be necessary for effective mathematics teaching (Trenholm, 2013). This contrasts with common practice in the general FO CoP where, for example, the timing between questions and responses is often more than 1 day (Mandernach, Gonzales, \& Garrett, 2006).

\section{Proctoring/invigilation}

One final difference concerns differing approaches to assessment and, in particular, the administration of summative assessment instruments (e.g. tests or exams). In general FO practice, there is an expectation of "anytime, anywhere" (or "100\% online") learning with concomitant pressure to offer all assessment instruments such that students may complete them on their own without human supervision (Trenholm, 2007). Such procedures are not aligned with typical F2F undergraduate mathematics assessment approaches where summative assessment instruments are dominant (Iannone \& Simpson, 2012) and typically invigilated ("proctored"; i.e. supervised by, for example, teachers or administrators).

In general FO practice, invigilation procedures may be put in place and, as discussed in the background, the administration of these instruments may involve additional human or computer resources requiring additional time and effort (Prince, Fulton, \& Garsombke, 2009). Perhaps understandably, some appear to be making efforts to mediate for the use of non-invigilated summative assessment instruments (Trenholm, Alcock, \& Robinson, 2015), as well as prove their reliability (Yates \& Beaudrie, 2009), though questions and concerns persist (Englander, Fask, \& Wang, 2011). Such mediational efforts appear consistent with efforts by the F2F mathematics CoP to adapt to the expectations and practices in the general FO CoP (Trenholm, et al., 2015).

\section{Limitations}

The above six differences represent the fruit of our deliberative study of this field both as researchers and FO mathematics teachers. We in no way wish to suggest these are the only differences that exist and recognise our work is influenced by factors such as 
the cultural milieu within which we have lived and taught, as well as, and not least, the stage of technological development we are experiencing in education. We present our analysis with these limitations in mind and now turn to discussing what we envision to be a way forward.

\section{Negotiating a fusion of horizons}

So what does this analysis tell us? What do we do? In this section we propose a way forward, casting differences in "ways of doing" as an opportunity where successful brokerage between CoPs may pay dividends in both modalities.

By doing so we also do not wish to suggest an unrealistic expectation of close alignment between the FO and F2F mathematics teaching communities. However, as we now discuss, we argue this exercise of comparison by juxtaposition presents an opportunity for the mathematics education community not only to reflect on its own community teaching practices, both FO and F2F, but also to consider ways to transform current practices, thereby opening up pathways of teaching which leverage ongoing technological innovations.

We begin by reflecting on the past.

\section{Glancing into the rear-view mirror}

The incidental effect of the Gutenberg technology on the societies which embraced it was to promote the pre-eminence of visual texts over oral commentaries. Within 100 years of its invention, scholarly learning had metamorphosed into tomes of linearly read manuscripts no longer reliant on the personal summaries of debate or dialogue. The ratio of exposition around the textual contents versus debate or conversational dialogue began to change. Spurred on by the advent of public schooling the standardization of textbooks soon followed. By the twentieth century, the use of textbooks had become one of the foundational pillars on which subsequent educational pedagogies were based, with the teacher as the primary expositor of that knowledge.

However, in the mid-1990's, with the opening of the Internet to the public, societies began to adopt this new technology for educational purposes, setting in motion another revolution in thinking and learning. It was McLuhan's (1964) memorable aphorism "the medium is the message" which sharply re-oriented current thinking away from the content of the message to the medium itself as having its own intrinsic effect on the participants. In educational terms, we were entering a period where, rather than simply re-directing or re-assembling teaching approaches, we were discovering that these new technologies reshaped them as well (Gadanidis \& Geiger, 2010). Slowly the transformation of the pedagogies began to infiltrate the communities of practice in which they resided - for, as Wenger (2010) had already argued, learning is not just located "in the head or outside it, but in the relationship between the person and the world" (p. 1). Good pedagogy in mathematics teaching acknowledges this and seeks to foster it within existing affordances and constraints.

\section{Telescoping into the future}

Wenger's (2010) concept of a CoP defined a regime of competence, or a set of criteria and expectations by which membership in that community is recognized. Part of the 
competency of a particular practice includes "understanding what matters, what the enterprise of the community is, and how it gives rise to a perspective on the world" (p. 2).

This paper attempts to showcase some of that competency in the era of digital learning, leading to a redefined CoP for the twenty-first century which has the potential to develop into a special kind of ethnographic culture of teaching and learning. In this new paradigm, some researchers do assert that FO teaching can promote a deeper and richer conceptual understanding of mathematical ideas because of its ready access to an array of technologies which elucidate mathematical abstractions using visualizations and visuospatializations (Mayer, 2009; Shah \& Miyake, 2005). Alternatively, still others claim, as large scale empirical research now suggests, that it is more difficult to teach mathematics effectively in the FO context due, in part, to the previously discussed issues of divergence (see Section 3). Nonetheless, a realignment in pedagogical approaches between the two communities of F2F and FO teaching is taking place on many continents around the globe. This phenomenon may, in part, be understood through the lens of history, in terms of the practices of teaching as having evolved out of the almost ubiquitous societal acceptance of the Gutenberg press, but which practices are now rapidly morphing into an altered form by adaptation through the use of digital technologies and online learning experiments.

\section{A parallax of perceptions}

Interestingly, it is the discipline of Mathematics which may provide some philosophical insight into the way forward. Mathematicians define "parallax" as the change of angular position of two lines of sight of a single object relative to each other as seen by an observer, caused by a change in the observer's position. The observer, it should be noted, often perceives it as a change in the location of the object, rather than a change in his/ her own position relative to that object. In contemporary writing, the meaning of parallax is singularly subjective and refers to a piece of writing told from a different perspective than that of another or similar stories of the same time period. In philosophy, the word parallax merges the two themes and creates an enigmatic perspective of knowing and understanding which is highly individual.

This metaphor of parallax may be extended into the teaching and learning of mathematical constructs. The "object," in this case, is the CoP associated with mathematics teaching. The "observer" is the teacher within that CoP. The teaching objectives have not changed. The move from F2F to FO classrooms is simply a change in the line of sight and how that modifies the individual's philosophical perspective of that object. The ensuing transformations in teaching pedagogy will contribute to the conversations about CoPs in this digital age. It was McLuhan who prophetically warned that "new media do not replace each other, they complicate each other" (as cited by Lamberti, 2011, p. xLi).

In this crucible of change, perhaps the most burning question concerns the role of the teacher. In the Gutenberg era, it could be said that the teacher was centre stage as the presenter or the arbitrator between the student and mathematical knowledge, primarily conveyed through paper texts or blackboard notes. In the FO context, one must consider whether the "ways of doing" in the FO mathematics CoP now involves a role that will only involve a few cameo appearances. 


\section{Changing places}

For those of us who are within the new and rapidly evolving FO CoP, ironically, and perhaps even surprisingly, it turns out that teachers are as ubiquitous in FO as in F2F classrooms: As a guide, the teacher participates in the design of the web site with its nested components providing a logical sequence of learning activities and multimedia events. As an expositor, the teacher creates course materials for those activities. As a motivator, the teacher provides feedback, thereby helping students adjust their everdeveloping thinking processes. As a mediator, the teacher offers extra online video tutorials or digitally-created resource materials. In so doing, the FO teacher's role evolves into one of a stage manager involving the arrangement and orchestration of all the media events contained within this enterprise. There, in this 24-7 virtual world, an implicit teacher presence permeates the students' entire learning process rather than being focused to specified weekly timeslots. Students determine their own pathways and set their own pace. This is a change of place for both teacher and learner. For those who are willing to venture into this new frontier, a smoother transition between F2F and FO places of learning may be realized by keeping in mind some fundamental pedagogical principles.

(1) Don't abandon the successes of the past altogether. The Gutenberg press transformed whole cultures into readers and writers. Rather, integrate the best of those practices into the future. That is, some reading should be required. This engages cognitive processes, promoting a personal interaction with the texts, separate from other media or the teacher.

(2) Keep the primary focus on the essence of what it is to learn mathematical concepts and what it takes to morph those snapshots of learning into a transformed selfidentity as a mathematical thinker. In mathematics classrooms, this encapsulates "understanding what matters, what the enterprise of the community is and how it gives rise to a perspective on the world" (Wenger, 2010, p.2). Moreover, it is independent of the educational setting. Albert Einstein provided some insight into what it means to be a mathematical thinker. In his personal notes, he alluded to thinking processes as beginning with the ability to form a mental image from sensory input (Einstein as cited by Barbatis, Leyva, Prabhu, Sidibe, \& Watson, 2012, p. 20). A series of such mental constructs still would not, in his opinion, constitute "thinking". In his mind, thinking would take place when the mind was able to provide an order or relation to a number of mental images so as to create a connection between them. At this moment of consolidation, an integrated concept - formed from a personal composition of mental imagery - would have been virtually reified. That, to him, was "thinking". By taking Einstein's lead, we may define mathematical thinking as a duplication of this mental process with theoretical and higher-order visuospatial thinking forming the basis of the mental images (see also Tall, 1991).

(3) Provide a kaleidoscope of ways to view your subject matter envisioned either in stratified pyramidal layers, as a series of concentric circles or as a tessellated mosaic - from its skeletal framework to its intricacies in order to reify its abstractions. These mosaic pieces constitute a multimodal, multidimensional and multimedia view of the world around us beginning with our personal sensory 
inputs, transformed through our affective and cognitive analytic processes, and ultimately creating in us a new "identity in difference" (Hegel, 1967).

When we talk about multimedia learning, we tend to overlook that F2F classrooms embody a natural world of interactive media options: textbooks, posters, lectures or recitations, animation (demonstrations and gestures) and interpersonal communication (discussion/question periods). From these past experiences of our own school days, we may draw parallels to virtual environments. Online multimedia presentations, as well, should, as much as possible, utilize dual channel, visual/pictorial and auditory/verbal, processing of information. Mayer (2009) proposed a cognitive theory of multimedia learning concluding that "meaningful learning occurs when learners engage in active processing within the channels including selecting relevant words and pictures, organizing them into coherent pictorial and verbal models, and integrating them with each other and appropriate prior knowledge" (p. 481). In short, three active processes are involved: selection, organization and integration. Each involves processing and interpreting information that is visuospatial and/or verbal/textual.

Therefore, in online learning environments, it behoves us to utilize proven design principles which enhance visuospatial thinking. Mayer's (2009) book, Multimedia Learning, provides a more complete treatise on ways to design online learning materials to match how individuals process information, noting that those having some difficulty learning mathematics benefit the most from well-designed and effective multimedia tools. Still we need to avoid online fireworks and spectacle which can be attention-getting, exciting and even memorable in its impact, but ultimately momentary and superficial in its import. Deep learning is fostered by revisiting the ideas at appropriate junctures, providing alternative viewings of the same object and allowing enough digestion time for them to be transformed into, what Grumet (1999) named, "an aesthetic object reflected into internal autobiography." In the end, this facilitates the kind of learning highlighted by Wenger (2010) as "not just acquiring skills and information; it is becoming a certain person - a knower in a context where what is means to know is negotiated with respect to a regime of competence of a community" (p.181).

We now turn to discuss how the FO environment and teaching practices present both challenges and opportunities for mathematics teaching.

\section{Circumventing hurdles}

Although different, we see the nature of communication, as within any community involved in the teaching of mathematics, is at the root of most, if not all six acknowledged issues discussed above. Of all the divergences between F2F and FO teaching discussed, this is perhaps the most serious given its potential to hinder or discourage human interaction; as Wenger (2010) argues, "engagement in social contexts involves a dual process of meaning making" which requires personal participation in an interplay with physical and/or conceptual artifacts (p. 1). That is, problems in communicating, whether personal or technical, can jeopardize the potential for meaningful learning. Yet problems with communicating mathematical ideas in an online environment are expected to persist. While new technologies are emerging to help overcome these 
challenges (e.g. MathML, Maple TA), more research is needed to help make online mathematical communication a more natural and universally understood process.

What may be both a potential help and a hurdle, the relative anonymity provided by the FO classroom has been viewed as a means to alleviate the tensions (e.g. potential embarrassment or intimidation) which some students experience when learning mathematics in a F2F setting. However, this same anonymity continues to present challenges when it comes to the administration of summative tests which currently dominate undergraduate mathematics assessment practices. As previously discussed, new approaches are being experimented with (Trenholm et al., 2015) and new technologies are being developed (Hylton, Levy, \& Dringus, 2016) to meet these challenges. Relatedly, some have suggested new formative assessment approaches. For example, providing students with carefully selected de-identified peer solutions to specific problems which they are asked to judge and compare (Jones \& Alcock, 2014). Such a student-led, but teacher guided process, aligned with current FO practices, would encourage students to engage in higher level thinking (Trenholm et al., 2016).

Indeed, while relatively low cycles of interactivity in the FO context may appear to inhibit the teaching of mathematics, they may, in fact, enable deeper learning. Longer personal mental background processing may provide the necessary time for better and more effective use of peer interactions. Longer cycles of interactivity can also provide students with more time to construct and rethink their thoughts, providing the necessary pause for analysis, reflection, cognitive assimilation and reassembly. Such a transformation would shift the responsibility of interactive teaching from the teacher to the students themselves (Olive et al., 2009).

\section{Traversing the zone of between}

Yet it could be argued that the issue at stake here is our reticence to change our position. We are trying to replicate our F2F teaching experience using these new digital technologies as "simple pedagogical adjuvant [s]" (Artigue, 2009, p. 467), rather than as conduits that lead to the transformation of current pedagogical practices. It is claimed, for example, that the FO environment affords a richer and more diverse network of learning opportunities which extend beyond the rhetorical overlay of Gutenbergian texts and diagrams. For example, the FO setting affords opportunities for interactive, configurable and re-viewable voice-over demonstrations and animations which may enhance the ability of teaching activities to reify the abstractions of mathematical language into a concrete understanding of specific processes or concepts. The uptake by some mainstream educational institutions to encourage this kind of online course development has been understandably slow. This may be partly because of a deeprooted academic resistance to change or partly because of the sometimes steep learning curve associated with creating these technological learning objects, which are continuously under development. This is not to mention a lack of resources to affect this kind of change.

However, for those who can cross this divide and explore new avenues of pedagogy, there is potential for an implicit metamorphosis to a more student-centred pedagogy in mathematics education, which has implications for student motivation, selfdetermination and achievement (Jaworski, 1994; Stein, Engle, Smith, \& Hughes, 2008). 
The inclusion of online resources allows the teacher to encourage students to investigate a vast network of exploratory channels which cover the material from diverse perspectives. Indeed, it could be argued that mathematics learning via the online medium is not an obstacle to deep learning because its natural form is a mosaic providing opportunities for students to reflect on multiple solution perspectives (Lampert, 1990).

\section{Conclusion}

In this paper, we uncover six differences in "ways of doing" in FO general versus traditional $F 2 F$ mathematics teaching practices. We argue these differences present opportunities for what many in the mathematics education community would consider desired changes, while others challenge the constraints of this medium and call for further exploration and development.

In particular, we believe there is potential for improving undergraduate mathematics teaching in the FO as well as the F2F contexts, each contributing to the benefit of advancing student learning and in ways to which the entire mathematics education community can only currently aspire (e.g. "why aren't we all learning math this way?": Alagic \& Alagic, 2013, p.23). One option for this transition comes from McLuhan's (1964) work on the virtual properties of communication media which led to his notion of a mosaic of language to impart the deeper meaning(s) of a text. Moreover, the idea of a FO learning space as a tessellated mosaic of activities coalesced by a network of links and embeddings, has the potential to lead to a multi-dimensional understanding (and deeper learning) of the complexity of mathematical methods and ideas.

Nonetheless, exploiting the potential of online education takes work, ingenuity, inventiveness, a willingness to experiment with new technologies, and a faith in your own abilities to teach - all with an attentive ear to your students' opinions. The sophistication of the new technologies and the abstractions of mathematical thought make the creation of an efficient and effective online learning environment a challenging task for mathematics educators (Mayer, 2009; Peschke, 2014a, 2014b). Nonetheless, we see the possibilities and, for those willing to help broker current differences, we end with the following principles:

(1) Resist dichotomizing pedagogies: one versus another. Rather adopt iterations of change from one to the other, where and when desirable and possible.

(2) Emulate the qualities of the new technological media: open to change, flexible and adaptable.

The negotiation between practitioners of FO general and F2F mathematics CoPs is not a two-becoming-one alloy of practice but is rather indicative of two fusing at their horizons of expertise. This is no less true of both F2F and FO CoPs in the teaching of mathematics.

Acknowledgements

The authors wish to thank Prof Barbara Jaworski for her helpful comments and feedback in the final write-up of this paper. 
Funding

Not applicable.

\section{Availability of data and materials}

Not applicable.

\section{Competing interests}

We declare no competing interests.

\section{Author details}

${ }^{1}$ School of Education, University of South Australia, Mawson Lakes Campus, Office G2-27 (Garth Boomer Building), Adelaide, SA 5095, Australia. ${ }^{2}$ Centre for Science, Faculty of Science \& Technology, Athabasca University, 1 University Dr, Athabasca, AB T9S 3A3, Canada.

Received: 5 November 2019 Accepted: 14 May 2020

Published online: 24 September 2020

\section{References}

Abdulwahed, M., Jaworski, B., \& Crawford, A. R. (2012). Innovative approaches to teaching mathematics in higher education: A review and critique. Nordic Studies in Mathematics Education, 17(2), 49-68.

Alagic, G., \& Alagic, M. (2013). Collaborative mathematics learning in online environments. In Visual mathematics and cyberlearning, (pp. 23-48). Netherlands: Springer.

Allen, l., \& Seaman, J. (2017). Digital learning compass: Distance education enrollment report 2017. Babson Survey Research Group. MA: USA.

Anderson, T., \& Elloumi, F. (2008). The theory and practice of online learning. Alberta: AU Press.

Artigue, M. (2009). The future of teaching and learning mathematics with digital technologies. In C. Hoyles, \& J.-B. Lagrange (Eds.), Mathematics education and technology - rethinking the terrain. The 17th ICMI study, (pp. 463-475). New York: Springer.

Arzarello, F., Paola, D., Robutti, O., \& Sabena, C. (2009). Gestures as semiotic resources in the mathematics classroom. Educational Studies in Mathematics, 70(2), 97-109.

Barbatis, P., Leyva, A., Prabhu, V., Sidibe, A., \& Watson, J. (2012). Engagement in creative thinking. Mathematics TeachingResearch Journal Online, 5(2). Retrieved May 27, 2020. https:/commons.hostos.cuny.edu/mtrj/wp-content/uploads/sites/3 0/2018/12/v5n2-Engagement-in-Creative-Thinking.pdf.

Biza, I., Jaworski, B., \& Hemmi, K. (2014). Communities in university mathematics. Research in Mathematics Education, 16(2), $161-176$.

Blair, R., Kirkman, E., \& Maxwell, J. W. (2012). Statistical abstract of undergraduate programs in the mathematical sciences in the United States: Fall 2010 conference board of mathematical sciences (CBMS) survey. Providence: American Mathematical Society.

Borba, M. C., Askar, P., Engelbrecht, J., Gadanidis, G., Llinares, S., \& Aguilar, M. S. (2016). Blended learning, e-learning and mobile learning in mathematics education. ZDM, 48(5), 589-610.

Chambers, F. C., \& Armour, K. M. (2011). Do as we do and not as we say: Teacher educators supporting student teachers to learn on teaching practice. Sport, Education and Society, 16(4), 527-544.

Confrey, J., \& Kazak, S. (2006). A thirty-year reflection on constructivism in mathematics education in PME. In A. Gutiérrez, \& P. Boero (Eds.), Handbook of research on the psychology of mathematics education: Past, present and future, (pp. 305-345). Rotterdam: Sense Publishers.

Correia, A. P., \& Davis, N. (2008). Intersecting communities of practice in distance education: The program team and the online course community. Distance Education, 29(3), 289-306.

Corriveau, C. (2017). Secondary-to-tertiary comparison through the lens of ways of doing mathematics in relation to functions: A study in collaboration with teachers. Educational Studies in Mathematics, 94(2), 139-160.

Covington, D., Petherbridge, D., \& Warren, S. E. (2005). Best practices: A triangulated support approach in transitioning faculty to online teaching. Online Journal of Distance Learning Administration, 8(1). Retrieved May 27, 2020. https://www.westga. edu/ distance/ojdla/spring81/covington81.pdf.

Cox, M. D. (2013). The impact of communities of practice in support of early-career academics. International Journal for Academic Development, 18(1), 18-30.

Edwards, L. D. (2009). Gestures and conceptual integration in mathematical talk. Educational Studies in Mathematics, 70(2), $127-141$.

Elbers, E. (2003). Classroom interaction as reflection: Learning and teaching mathematics in a community of inquiry. Educational Studies in Mathematics, 54(1), 77-99.

Engelbrecht, J., \& Harding, A. (2005). Teaching undergraduate mathematics on the internet: Parts I and II. Educational Studies in Mathematics, 58(2), 235-276.

Englander, F., Fask, A., \& Wang, Z. (2011). Comment on 'the impact of online assessment on grades in community college distance education mathematics courses' by Ronald W. Yates and Brian Beaudrie. American Journal of Distance Education, 25(2), 114-120.

Entwistle, N. (2009). Teaching for understanding at university. Deep approaches and distinctive ways of thinking. Basingstoke: Palgrave Macmillan.

Everson, M. G., \& Garfield, J. (2008). An innovative approach to teaching online statistics courses. Technology Innovations in Statistics Education, 2(1). Retrieved May 27, 2020. https://escholarship.org/uc/item/2v6124xr.

Finnegan, C., Morris, L. V., \& Lee, K. (2009). Differences by course discipline on student behavior, persistence, and achievement in online courses of undergraduate general education. Journal of College Student Retention: Research, Theory and Practice, 10(1), 39-54. 
Gadanidis, G., \& Geiger, V. (2010). A social perspective on technology-enhanced mathematical learning: From collaboration to performance (report). ZDM, 42(1), 91.

Glass, J., \& Sue, V. (2008). Student preferences, satisfaction, and perceived learning in an online mathematics class. Journal of Online Learning and Teaching, 4(3), 325-338.

Grumet, M. R. (1999). Autobiography and reconceptualization. In W. F. Pinar (Ed.), Contemporary curriculum discourses: Twenty years of JCT, (pp. 25-29). New York: Peter Lang.

Hegel, G. (1967). Phenomenology of mind. (J. B. Baillie, Trans.). London: Harper \& Row (Original work published 1807).

Hrastinski, S., \& Stenbom, S. (2013). Student-student online coaching: Conceptualizing an emerging learning activity. The Internet and Higher Education, 16, 66-69.

Hylton, K., Levy, Y., \& Dringus, L. P. (2016). Utilizing webcam-based proctoring to deter misconduct in online exams. Computers \& Education, 92, 53-63.

lannone, P., \& Simpson, A. (2012). A survey of current assessment practices. In P. lannone, \& A. Simpson (Eds.), Mapping university mathematics assessment practices, (pp. 3-15). UK: University of East Anglia.

Jaworski, B. (1994). Investigating mathematics teaching: A constructivist enquiry. London: The Falmer Press.

Jaworski, B. (2009). The practice of (university) mathematics teaching: Mediational inquiry in a community of practice or an activity system. In V. Durand-Guerrier, S. Soury-Lavergne, \& F. Arzarello (Eds.), Proceedings of CERME, (vol. 6, pp. 1585-1594).

Jones, I., \& Alcock, L. (2014). Peer assessment without assessment criteria. Studies in Higher Education, 39(10), 1774-1787.

Keady, G., Fitz-Gerald, G., Gamble, G., \& Sangwin, C. (2012). Computer-aided assessment in mathematical sciences. In Proceedings of the $18^{\text {th }}$ Australian conference on science and mathematics education (formerly UniServe Science Conference), (pp. 69-73).

King, D., \& Cattlin, J. (2017). Building a network and finding a community of practice for undergraduate mathematics lecturers. In Implementing communities of practice in higher education, (pp. 29-51). Singapore: Springer.

Kisiel, J. F. (2010). Exploring a school-aquarium collaboration: An intersection of communities of practice. Science Education, 94(1), 95-121.

Lamberti, E. (2011). Not just a book on media: Extending the Gutenberg Galaxy. In M. McLuhan (Ed.), The Gutenberg Galaxy (2011 edition), (pp. xxv-xLv). Toronto: University of Toronto Press.

Lampert, M. (1990). When the problem is not the question and the solution is not the answer: Mathematical knowing and teaching. American Educational Research Journal, 27(1), 29-63.

Lave, J., \& Wenger, E. (1991). Situated learning: Legitimate peripheral participation. New York: Cambridge University Press.

Lerman, S. (2014). Wait time in mathematics teaching. In Encyclopedia of mathematics education, (p. 641). Netherlands: Springer.

Lokken, F. (2011). 2010 distance education survey results - trends in e-learning: Tracking the impact of e-learning at community colleges. Washington, D.C.: Instructional Technology Council.

Lowrie, T., \& Jorgensen, R. (2012). Teaching mathematics remotely: Changed practices in distance education. Mathematics Education Research Journal, 24(3), 371-383.

Mandernach, B. J., Gonzales, R., \& Garrett, A. L. (2006). An examination of online instructor presence via threaded discussion participation. Journal of Online Learning and Teaching, 2(4), 248-260,

Mayer, R. E. (2009). Multi-media learning, (2nd ed., ). New York: Cambridge University Press.

McLuhan, M. (1964). Understanding media: The extensions of man. New York: McGraw Hill.

Miller, M. D. (2014). Minds online: Teaching effectively with technology. Boston: Harvard University Press.

Mills, J. D., \& Raju, D. (2011). Teaching statistics online: A Decade's review of the literature about what works. Journal of Statistics Education, 19(2). Retrieved May 27, 2020. https://www.tandfonline.com/doi/abs/10.1080/10691898.2011.11889613

Moore, M. G. (2007). The theory of transactional distance. In M. G. Moore, \& W. G. Anderson (Eds.), Handbook of distance education, (2nd ed., pp. 89-104). Mahwah: Lawrence Erlbaum.

Nelson Laird, T. F., Shoup, R., Kuh, G. D., \& Schwarz, M. J. (2008). The effects of discipline on deep approaches to student learning and college outcomes. Research in Higher Education, 49(6), 469-494.

Olive, J., Makar, K., Hoyos, V., Kor, L. K., Kosheleva, O., \& Strässer, R. (2009). Mathematical knowledge and practices resulting from access to digital technologies. In Mathematics education and technology-rethinking the terrain, (pp. 133-177). US: Springer.

Peschke, J. (2014a). A case study of teaching and learning mathematics online. Canada: PhD dissertation, University of Alberta.

Peschke, J. (2014b). Where is the teacher in online learning: Centre stage or cameo appearance? In Proceedings of the European distance and e-learning network 2014 research workshop, (pp. 47-55).

Prieto, E., \& Holmes, K. (2014). Online students' perceptions of interactive tools to support postgraduate learning of mathematics. In J. Anderson, M. Cavanagh, \& A. Prescott (Eds.), Curriculum in focus: Research guided practice, Proceedings of the 37th annual conference of the Mathematics Education Research Group of Australasia, (pp. 525-533).

Prince, D. J., Fulton, R. A., \& Garsombke, T. W. (2009). Comparisons of proctored versus non-proctored testing strategies in graduate distance education curriculum. Journal of College Teaching \& Learning, 6(7), 51-62.

Radford, L. (2008). Diagrammatic thinking: Notes on Peirce's semiotics and epistemology. PNA: Revista de Investigación en Didáctica de la Matemática, 3(1), 1-18.

Riesland, E., Jacobson, J., Snare, J., \& Fehrenbacher, R. (2016). A faculty-led community of practice approach to course development in online environments. In EdMedia: World conference on educational media and technology, (pp. 724-728). Vancouver: Association for the Advancement of Computing in Education (AACE).

Roos, H., \& Palmér, H. (2015). Communities of practice: Exploring the diverse use of a theory. In CERME 9-ninth congress of the European society for research in mathematics education, (pp. 2702-2708).

Rosa, M., \& Lerman, S. (2011). Researching online mathematics education: Opening a space for virtual learner identities. Educational Studies in Mathematics, 78(1), 69-90.

Roth, W. M. (2001). Gestures: Their role in teaching and learning. Review of Educational Research, 71(3), 365-392.

Rovai, A. P. (2004). A constructivist approach to online college learning. The Internet and Higher Education, 7(2), 79-93.

Sfard, A. (2014). University mathematics as a discourse - Why, how, and what for? Research in Mathematics Education, 16, 199-203. 
Shah, P., \& Miyake, A. (2005). Preface. In P. Shah, \& A. Miyake (Eds.), The Cambridge handbook of visuospatial thinking, (pp. xixv). New York: Cambridge University Press.

Smith, G. G., Ferguson, D., \& Caris, M. (2003). The web versus the classroom: Instructor experiences in discussion-based and mathematics-based disciplines. Journal of Educational Computing Research, 29(1), 29-59.

Smith, G. G., Torres-Ayala, A. T., \& Heindel, A. J. (2008). Disciplinary differences in E-learning instructional design. Journal of Distance Education, 22(3), 63-88.

Smith, S. U., Hayes, S., \& Shea, P. (2017). A critical review of the use of Wenger's Community of Practice (CoP) theoretical framework in online and blended learning research, 2000-2014. Online Learning, 21(1), 209-237.

Stein, M. K., Engle, R. A., Smith, M. S., \& Hughes, E. K. (2008). Orchestrating productive mathematical discussions: Five practices for helping teachers move beyond show and tell. Mathematical Thinking and Learning, 10, 313-340.

Swan, K. (2003). Learning effectiveness online: What the research tells us. In J. Bourne, \& J. C. Moore (Eds.), Elements of quality online education, practice and direction, (pp. 13-45). Needham: Sloan Center for Online Education.

Tall, D. (Ed.) (1991). Advanced mathematical thinking. New York: Kluwer Academic.

Trenholm, S. (2007). A review of cheating in fully asynchronous online courses: A math or fact-based course perspective. Journal of Educational Technology Systems, 35(3), (pp. 281-300).

Trenholm, S. (2013). Adaptation of tertiary mathematics instruction to the virtual medium: Approaches to assessment practice. (Unpublished PhD). East Midlands: Loughborough University.

Trenholm, S., Alcock, L., \& Robinson, C. (2015). An investigation of assessment and feedback practices in fully asynchronous online undergraduate mathematics courses. International Journal of Mathematical Education in Science and Technology, 46(8), 1197-1221.

Trenholm, S., Alcock, L., \& Robinson, C. (2016). The instructor experience of fully online tertiary mathematics: A challenge and an opportunity. Journal for Research in Mathematics Education, 47(2), 147-161.

Trenholm, S., Peschke, J., \& Chinnappan, M. (2019). A review of fully online undergraduate mathematics instruction through the lens of large-scale research (2000-2015). PRIMUS, 29(10), p. 1080-1100

Velez-Solic, A., \& Banas, J. (2012). Professional development for online educators: Problems, predictions, and best practices. In Virtual mentoring for teacher: Online professional development practices, (pp. 204-226).

Vilardi, R., \& Rice, M. L. (2014). Mathematics achievement: Traditional instruction and technology-assisted course delivery methods. Journal of Interactive Online Learning, 13(1). Retrieved May 27, 2020. https://www.ncolr.org/jiol/issues/pdf/13.1.2. pdf.

Viskovic, A. (2006). Becoming a tertiary teacher: Learning in communities of practice. Higher Education Research \& Development, 25(4), 323-339.

Voloshinov, V. N. (1973). Marxism and the philosophy of language. Cambridge: Harvard University Press.

Wenger, E. (1998). Communities of practice. Cambridge: Cambridge University Press.

Wenger, E. (2010). Communities of practice and social learning systems: The career of a concept. In C. Blackmore (Ed.), Social learning systems and communities of practice. UK: The Open University, Springer Verlag.

Woo, K., Gosper, M., McNeill, M., Preston, G., Green, D., \& Phillips, R. (2008). Web-based lecture technologies: Blurring the boundaries between face-to-face and distance learning. ALT-J, 16(2), 81-93.

Xu, D., \& Jaggars, S. S. (2011). The effectiveness of distance education across Virginia's community colleges: Evidence from introductory college-level math and English courses. Educational Evaluation and Policy Analysis, 33(3), 360-377.

Yates, R. W., \& Beaudrie, B. (2009). The impact of online assessment on grades in community college distance education mathematics courses. The American Journal of Distance Education, 23(2), 62-70.

\section{Publisher's Note}

Springer Nature remains neutral with regard to jurisdictional claims in published maps and institutional affiliations.

\section{Submit your manuscript to a SpringerOpen ${ }^{\circ}$ journal and benefit from:}

- Convenient online submission

- Rigorous peer review

- Open access: articles freely available online

- High visibility within the field

- Retaining the copyright to your article

Submit your next manuscript at $\mathbf{s p r i n g e r o p e n . c o m ~}$ 